\title{
Akut Apandisitin Nadir Nedeni Apendiks Divertikülitleri
}

\author{
A Rare Cause of Acute Appendicitis: Diverticulitis of the Appendix
}

\author{
${ }^{1}$ Aylin Hande Gökçe, ${ }^{2}$ Acar Aren \\ ${ }^{1}$ İstanbul Medicine Hospital, Genel Cerrahi Kliniği, İstanbul, Türkiye \\ ${ }^{2}$ İstanbul Eğitim ve Araştırma Hastanesi, Genel Cerrahi Kliniği, İstanbul, Türkiye
}

Özet: Apendiks divertikülitleri akut apandisitin çok ender nedenlerindendir. Akut karına neden olan apendiks divertiküllerinin görülme sıklığı, yaş ortalaması, cinsiyet dağılımı, divertikül sayısı ve lökosit oranları karşılaştırıldı. Kliniğimizde akut karın nedeniyle yapılan apendektomi olguları apendiks divertikülitleri açısından retrospektif olarak araştıııldı. Hastanemizde son 5 yılda 1775 apendektomi yapılmıştı. Bu piyeslerin 32'sinde (\%1.80) apendiks divertiküliti saptandı. Apendiks divertiküliti tanısı konan olguların yaş ortalaması 35.3 yıl idi. Otuziki hastanın 24’ü (\%75) erkek, sekizi (\%25) kadındır. Patoloji piyesindeki divertikül sayısına bakıldığında 23'ünde bir divertikül (\%71.9), dokuzunda (\%28.1) ise iki veya daha fazla divertikül saptandı. Ameliyat öncesi lökosit sayısı olguların 23'ünde (\%71.9)'ünde $11.000 / \mathrm{mm}^{3}$ ve üzeri, dokuzunda $(\% 28.1)$ ise $11.000 / \mathrm{mm}^{3}$ 'ün altında idi. Ameliyat öncesi yapılan ultrasonografide 29 olguda (\%90.6) akut apandisit bulguları saptandı, üç olguda ise (\%9.4) ise akut apandisit lehine bulgu saptanmadı. Divertikül sayısı bir olanlar ile iki ve üzeri olanların yaş ortalamaları, cinsiyet dağılımları, lökosit oranları ve ultrasonografi sonuçları arasında istatistiksel olarak anlamlı fark gözlenmemiștir (tümü için p>0.05). Apendiks divertikülünün akut karın tablosuyla karşımıza çıkma yaş ortalaması, diğer akut apandisit nedenlerinde olduğu gibi genç yaşlardır. Akut karına neden olmuş apendiks divertiküliti erkeklerde daha sık görülmüștür. Akut apandisitten șüphelenilen ve uzun preoperatif semptomlara sahip hastalarda appendiks divertiküliti akılda tutulmalıdır. Yüksek perforasyon oranları nedeniyle preoperatif şüphe halinde erken cerrahi uygulanmasının uygun olduğu düşüncesindeyiz.

Anahtar Kelimeler: akut apandisit, apendiks divertiküli, apendiks divertiküliti, apendektomi

Abstract: Acute appendicitis is the most common surgical emergency while diverticulitis of the appendix is a rare cause of appendicitis. The incidence of diverticulitis of the appendix leading to acute abdomen, the age at diagnosis, sex distribution, number of diverticula and leucocytes counts were assessed in this study.We retrospectively investigated appendectomy procedures performed in our clinic in patients with acute abdomen. A total of 1775 appendectomy procedures were performed in our hospital during the last 5 years. Diverticulitis of the appendix was detected in $32(1.80 \%)$ of those pathology specimens. The mean age was 35.3 years in study patients who underwent surgery as a result diverticulitis of the appendix. Twenty-four (\%75) out of these 32 patients were male and eight patients $(25 \%)$ were female. In the assessment of pathology specimens by the number of diverticula, one diverticulum was detected in 23 pieces $(71.9 \%)$ and $\geq 2$ diverticula were detected in nine pieces. Preoperative leukocyte counts were $\geq 11.000 / \mathrm{mm}^{3}$ in 23 patients $(71.9 \%)$ and $<11.000 \mathrm{~mm}^{3}$ in nine patients $(28.1 \%)$ with diverticulitis of the appendix. The signs of acute appendicitis were detected in 29 out of 32 patients $(90.6 \%)$ during preoperative ultrasound exams, while any signs indicating acute appendicitis were not detected in three patients $(9.4 \%)$. No statistically significant differences were found between patients who had a single diverticulum and patients with multiple diverticula in the mean age, sex distribution, leukocyte counts, and ultrasound findings ( $>0.05$ for all). As with patients with acute appendicitis, patients who presented with the signs and symptoms of acute abdomen associated with diverticulitis of the appendix were young, A male predominance was observed in cases of diverticulitis of the appendix associated with acute abdomen. Appendix diverticula should be carefully considered in patients with long-term preoperative symptoms that raise suspicion of acute appendicitis. Early surgery is indicated in case of any preoperative suspicion of diverticulitis of the appendix, as diverticulitis is associated with high perforation rates.

Keywords: acute appendicitis, appendix, diverticulosis, appendiceal diverticulitis, appendectomy

ORCID ID of the authors: A.H.G. 0000-0003-1908-2889, A.E. 0000-0001-6797-3657 


\section{Giriș}

En sık akut karın sebebi akut apandisittir. Apendiks vermiformiste yer alan divertikülitler ilk kez 1893 y1lında Kelynak tarafından tanımlanmıştır (1). Çok nadir görülen oluşumlardır. Apendiks divertikülitinin görülme sıklığı $\% 0.004$ ile \%2.1 arasında değişiklik göstermektedir. Cerrahlar apendiks divertiküliti tanısını kolaylıkla atlayabilmektedirler. $\mathrm{Bu}$ yüzden çoğunlukla cerrahi sonrası patolojik inceleme sonunda tanı konulabilmektedir. Akut apendisit'te apendiks divertikülitinde de klinik bulgular benzerlik gösterir. Ancak, tanıda gecikme ve divertikülün anatomik özellikleri nedeniyle apendiks divertikülitli hastalar akut apandisitli olgulara göre daha fazla ve çabuk perfore olmaktadır (2). Apendiks divertikülleri genellikle inflamasyon gelişmediği sürece asemptomatik seyretmektedirler $(1,3)$. Diğer tüm divertiküller gibi konjenital (gerçek) ya da edinsel (yalanc1) olarak sinıflandırılmaktadırlar $(1,4)$. Patolojik olarak konjenital divertiküllerin duvar yapısında musküler kat yer alırken edinsel divertiküllerde bulunmamaktadır. Anatomik özellikler divertikül perforasyonuna neden olan ana etmenlerdendir. Bu nedenle edinsel divertiküllerin perforasyon riskleri yüksektir. Perforasyon geliştiğinde hafif inflamasyon nedeniyle periumblikal ağrı gibi nonspesifik semptomlar oluşur. Kısa zaman sonra tam lokalize edilemeyen bir ağriyla beraber abse gelişebilir. Operasyon öncesi semptomatik dönemin uzun olması apendiks divertiküllü hastalarda intraperitoneal abse ve perforasyon gelişme riskini artırır. Lipton ve arkadaşları (5) apendiks divertikülitli hastalarında perforasyon oranını \%66, Yamana ve arkadaşları (6) \%33 olarak bildirmektedir. $\mathrm{Bu}$ oran perfore akut apandisit hastalarından 4 kat daha fazladır (5-6). Çalışmamızda akut karına neden olan apendiks divertiküllerinin görülme sıklığı, yaş ortalaması, cinsiyet dağılımı, divertikül sayısı, lökosit oranları ve operasyon öncesi yapılan ultrasonografilerde akut apandisit ön tanısı oranı araştırıldı.

\section{Materyal ve Metot}

Çalışma retrospektif kohort yöntemiyle yapılmıştır ve etik kurul onayı alınmıştır (2011-KAEK-50-1384). Klinikte beş yılda akut karın nedeniyle yapılan apendektomi olguları apendiks divertikülleri açısından retrospektif olarak araştırıldı. Tanıda apendiks preparatları hematoksilen eozin boyasıyla boyanıp apendiks duvarında divertikül olduğu saptanan olgular çalışmaya alındı (Şekil 1). Apendiks piyeslerinin histopatolojisinde divertikül saptanan olgular arasında apendiks duvarında bir divertikülü olanlar Grup 1, iki veya daha fazla divertikülü olanlar Grup 2 olarak kabul edildi.

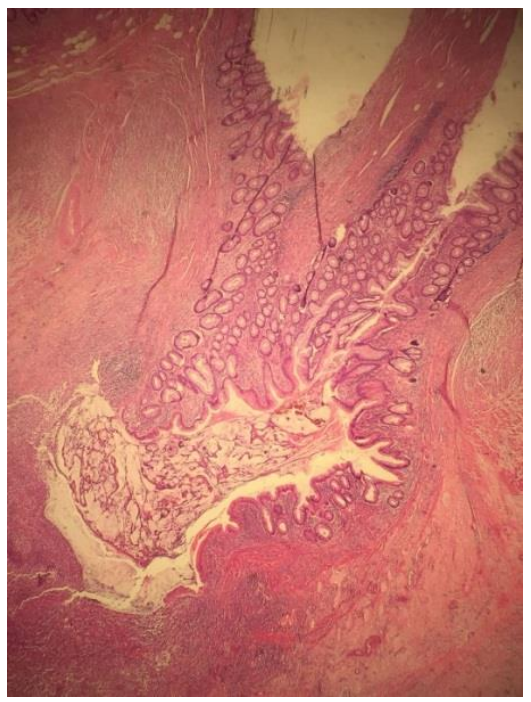

Şekil 1. Hematoksilen eozin boyasıyla boyanmış apendiks duvarında divertikül ve divertikülit varlı̆̆ 


\section{İstatistik analiz}

İstatistiksel Analiz Veriler SPSS 22.0 (Statistical Package for Social Sciences, Windows) programı ile analiz edildi. Sürekli değişkenler ortalama ve standart dağılım olarak belirtildi. Normal dağglım gösterip göstermemesine göre Student's $t$ test veya Mann-Whitney U-test'i kullanılarak sürekli değişkenler gruplar arasında karşılaştırıldı. İstatistiksel olarak $p<0,05$ değeri anlamlı olarak kabul edildi.

\section{Bulgular}

Hastanemizde 5 yılda apendektomi yapılan olgu say1s1 1775 di. $\mathrm{Bu}$ apendektomi piyeslerinin histopatolojisinde 32 olguda apendiks divertiküliti saptanmıştır. Çalışmada apendektomilerin \% 1.80 'inde apendiks divertikülleri saptanmıtır. Apendiks divertikülitli oguların yaş ortalaması 35.3 yıldır. Olguların 24'ü (\%75) erkek, sekizi (\%25) kadındır. Histopatolojisinde divertikül sayısına bakıldığında 23 'ünde (\%71.9) bir divertikül, dokuzunda (\%28.1) iki veya daha fazla divertikül saptanmıştır. Ameliyat öncesi lökosit sayısı olguların 23'ünde (\%71.9) $11.000 / \mathrm{mm}^{3}$ ve üzeri, dokuzunda $(\% 28.1)$ ise $11.000 / \mathrm{mm}^{3}$ altında idi. Ameliyat öncesi yapilan ultrasonografide 29 olguda (\%90.6) akut apandisit bulguları saptanmış, üç olgusa ise (\%9.4) ise akut apandisit lehine bulgu saptanmamıştı. Apendiks divertiküliti saptanan 32 olgunun 11'inde (\%34.4) perforasyon saptandı. Divertikül sayıs1 bir olanlar ile iki ve üzeri olanların yaş ortalamaları $(\mathrm{p}=0.294)$, cinsiyet dağ 1 lımları $(\mathrm{p}=0.654)$, lökosit oranları $(\mathrm{p}=0.31)$ ve ultrasonografi sonuçları $(\mathrm{p}=0.938)$ arasında istatistiksel olarak anlamlı fark gözlenmemiştir.

\section{Tartışma}

Apendiks divertikülitinin görülme sıklığ $\%$ 0.004 ile \% 2.1 arasında değişiklik göstermektedir (2). Bu çalışmada da literatür ile uyumlu olarak \%1.8 saptanmıştır. Yamana ve arkadaşlarının (6) çalışmasında apendiks diveriküliti için ortalama yaş 42.7 yıl olarak bildirilmiştir. Yine aynı çalışmada apandisitli hastalarda etken olarak apendiks divertiküliti sıklığının yaşla beraber arttığı söylenmiştir
(6). Bizim çalışmamızda Yamana ve arkadaşlarının (6) çalışmasının aksine apendiks divertiküliti saptanma yaşı 35.3 yıl olup gençlerde sıklığı daha fazla saptandı. Yani çalışmamızda apendiks divertikülitlerinin akut karın tablosuyla karşımıza çıkma yaş ortalaması aynı diğer akut apandisit nedenleri gibi genç yaştaydı. Majeski ve arkadaşlarının (3) yaptığ çalışmada apendiks divertiküllerinin genellikle semptomsuz olduğu ve nadiren komplikasyonlara yol açtığı belirtilmekte, bazı yayınlarda ise hastaların üçte ikisine yakın kısmında divertikülit gelişebileceği, perforasyon riskinin yüksek olduğu, bu nedenle dikkatli olunması gerektiği belirtilmektedir (3). Lipton ve arkadaşları (5) apendiks divertikülitli hastalarında perforasyon oranını \%66, Yamana ve arkadaşları (6) \%33 olarak bildirmektedir. Çalışmada literatürlere uygun olarak perforasyon oran $1 \% 34.3$ olarak saptanmıştır. Apendiks divertikülitlerinin tedavisi konusunda değişik görüşler mevcuttur. Çeşitli yayınlarda, başka nedenlerle laparotomi yapılmış hastalarda rastlanan klinik olarak sessiz appendiks divertikülitlerinde yüksek perforasyon riski nedeniyle apendektomi yapılması önerilmektedir (4). Fakat apendiks divertikülitlerinin genelde küçük olması ve mezenterik tarafta yerleşmesinden dolay1 peroperatif tespit edilmesi kolay değildir. Dolayısıyla laparotomide tanıyı koymak kolay değildir. Genelde tanı histopatolojik inceleme ile konur (7).

Literatürde apendiks divertikülleri etyopatogenezinde nöroendokrin tümörlerin varlığ1 ve birlikteliği bildirilmiştir (8). Fakat çalışmamızda nöroendokrin tümör saptamadık. Çalışmada divertikül sayısı 1 olanlar ile 2 ve üzeri olanların yaş ortalamaları, cinsiyet dağılımları, lökosit oranları ve ultrasonografi sonuçları arasında istatistiksel olarak anlaml fark gözlenmedi. $\mathrm{Bu}$ konu ile ilgili literatürde çalışma olmadığ 1 için ileri yorum yapamadık. 


\section{Sonuç}

Akut karın yapmış olan apendiks divertiküliti erkeklerde daha sık görülmüştür. Akut karın yapmış olan apendiks divertiküliti erkeklerde daha s1k görülmüştür. Bütün apendiks divertiküllerimi yoksa sadece akut karın yapan apendiks divertiküllerinin mi erkeklerde daha s1k olduğunun araștırılması gerektiğini düşünmekteyiz. Çalışmada olduğu gibi apendiks divertikülitlerinin yaptığı akut apandisit tablosunda perforasyon riski diğer nedenlerden dolayı olan akut apandisitten çok daha yüksektir. Klinik şüphe halinde apendektomiyi olabildiğince erken yapmamız gerektiği ayrıca başka nedenlerle yapılan laparotomi/laparoskopide rastlantısal olarak apendiks divertikülü saptanırsa yine apendektomi yapılması gerektiği düşüncesindeyiz.

\section{KAYNAKLAR}

1. Bozkurt MK, Teztel S, Gözübüyük SH, Taner D, Taner Ş, Öngen C. Appendiks divertiküliti. Tur J Gastroenterol. 1992; 3: 179-81.

2. Sohn TJ, Chang YS, Kang JH, Kim DH, Lee TS, Han JK et al. Clinical characteristics of acute appendiceal diverticulitis. J Korean Surg Soc. 2013; 84: 33-7.

3. Majeski J. Diverticulum of the vermiform appendix is associated with chronic abdominal pain. Am J Surg. 2003; 186:129-31.

4. Greenberg R, Avital S, Kashtan H, Skornik Y. Diverticular disease of the appendix. Harefuah 1997; 132: 180-2.

5. Lipton S, Estrin J, Glasser I. Diverticular disease of the appendix. Surg Gynecol Obstet. 1989; 168: 13-6.

6. Yamana I, Kawamoto S, Inada K, Nagao S, Yoshida T, Yamashita Y. Clinical characteristics of 12 cases of appendiceal diverticulitis: a comparison with 378 cases of acute appendicitis. Surg Today. 2012; 42: 363-7

7. Kaymak Ş, Şenocak R, Alakuş Ü, Yiğit N. Apendiks divertiküliti: akut apandisitten farklı bir olgu. Cukurova Med J. 2016; 41: 815-7

8. Käser SA, Willi N, Maurer CA. Prevalence and clinical implications of diverticulosis of the vermiform appendix. J Int Med Res. 2013;41: 1350-6. 